\title{
What Signs and Symptoms Would Be Expected after Ingestion of this Plant? (From page 62)
}

\author{
Samuel J. Stellpflug, MD, Carson R. Harris, MD
}

Regions Hospital Department of Emergency Medicine and Clinical Toxicology Service, St. Paul, MN

\begin{abstract}
Answer: Datura stramonium ingestion produces the anticholinergic toxidrome.

A 49-year-old Southeast Asian man presented to the emergency department (ED) by ambulance with altered mental status. En route to the hospital the paramedics noted that the patient had intermittent combativeness and somnolence, reddish skin, tachycardia, hypertension, and mydriasis. Upon arrival to the ED the patient continued to have altered mentation, was hypertensive, tachycardic, and tachypneic, but noted to have "normal skin color with good capillary refill." He was dry everywhere, and had no appreciable bowel sounds. He had a normal fingerstick glucose. To facilitate the safe completion of the workup and to protect the airway, he was sedated and intubated. While the laboratory studies and head computed tomography (CT) were pending, the patient's family arrived and his Hmong-speaking wife was able to provide some history through an interpreter. Earlier that morning she received a few leaves of a plant from her neighbor's yard and was told by her mother and the neighbor that the leaves would help her husband's recent stomach cramping and irritation. She tore three of the leaves into pieces, mixed them with raw eggs, cooked them, and gave them to her husband. He reported that the eggs "tasted funny" and that his mouth was getting "numb." She then witnessed his manner change significantly over the next 30 minutes. He became "crazy," with "different eyes" and "red cheeks." He was not responding appropriately to her or the family, prompting her
\end{abstract}

to call for an ambulance. She gave his past medical history of hypertension and "some kidney problems." The patient's workup included a negative head CT and laboratory studies that were consistent with end-stage renal disease and no other abnormalities. He was admitted to the ICU for observation and supportive care. His mental status, tachycardia, abnormal pupils, and bowel sounds all normalized in the subsequent 24 hours. He was discharged home approximately 48 hours after initial presentation.

One of the leaves the wife had collected is shown in the accompanying photograph (Figure 1). Note the oval acute leaf deeply cut into uneven lobes, which are pointed and marked by prominent veins on the underside. The plant that produces this leaf is Datura stramonium (jimson weed); it also produces a tubular flower that widens like a trumpet at the end and a spiky capsule seed-producing fruit (1). The two botanists who evaluated this leaf identified it as $D$ stramonium based on its structural differences to the other 2 types of Datura indigenous to the area ( $D$ wrightii and $D$ inoxia). All parts of this plant can be poisonous due to the alkaloid anticholinergics atropine, hyoscyamine, and scopolamine, but the highest concentration of these alkaloids is in the seeds (2). The common symptoms from $D$ stramonium ingestion are similar to our case: altered mental status, agitation, combativeness, tachycardia, dry mouth, and mydriasis. The worst reported manifestation of the ingestion is death (3).

Keywords: Datura stramonium, jimson weed, anticholinergic Notes: The authors have no potential financial conflicts of interest to report. Corresponding author: Samuel J. Stellpflug, MD, Regions Hospital Department of Emergency Medicine and Clinical Toxicology Service, St. Paul, MN. Email: Samuel.J.Stellpflug@HealthPartners.com 


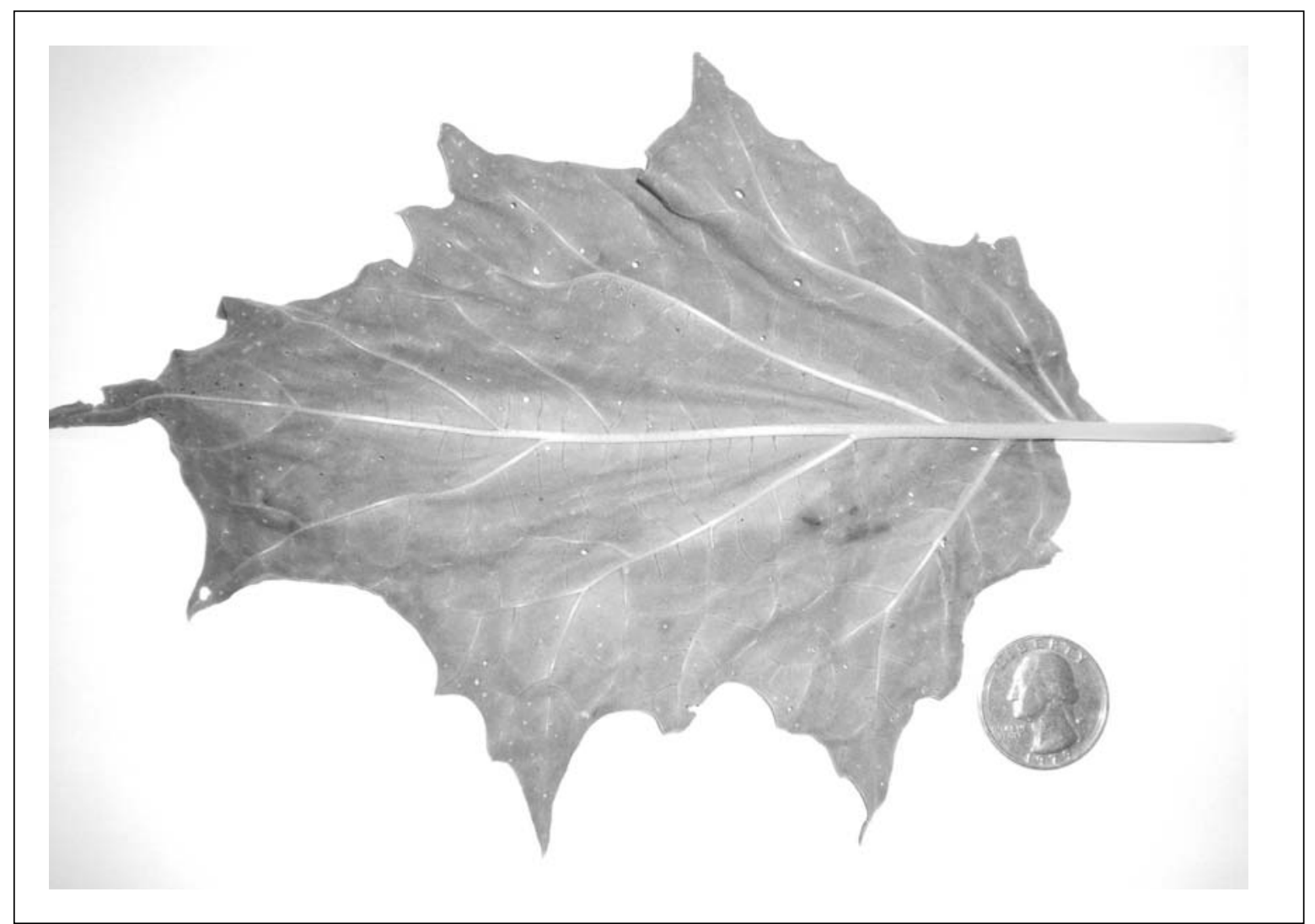

Figure 1: Underside of a Datura stramonium (jimson weed) leaf.

\section{REFERENCES}

1. Bruneton J. Solanaceae. In: Bruneton J, ed. Translated by Hatton CK. Toxic Plants: Dangerous to Humans and Animals. Secaucus, NJ: Lavoisier Publishing, 1999: 461-496.

2. Ellenhorn MJ. Plants-Mycotoxins-Mushrooms. In: Ellen- horn MJ, Schonwald S, Ordog G, Wasserberger J, eds. Ellenhorn's Medical Toxicology. 2nd ed. Baltimore: Williams \& Wilkins, 1997: 1832-1896.

3. CDC Publication. Epidemiologic Notes and Reports Jimson Weed Poisoning-Texas, New York, and California, 1994. MMWR $1995 ; 44(3) ; 41-44$. 